\title{
0
}

OLHARES

REVISTA DO DEPARTAMENTO DE EDUCAÇÃO - UNIFESP

\section{O lúdico na geografia: possibilidades e limites no ensino fundamental}

\author{
Denize Tomaz de Aquino \\ Universidade de Pernambuco-UPE/Campus Garanhuns \\ denize.aquino@upe.br \\ Marlene Burégio Freitas \\ Universidade de Pernambuco-UPE/Campus Garanhuns \\ marleneburegio162@gmail.com \\ Thainá Santos Sobral \\ Universidade de Pernambuco-UPE/Campus Garanhuns \\ thainasantos.2011@hotmail.com \\ José Lucas dos Santos \\ Universidade de Pernambuco-UPE/Campus Garanhuns \\ Jooseluccas2004@gmail.com
}

\section{RESUMO}

A presente investigação tem como objetivo propor a interação teoria-prática, no sentido de transformar a sala de aula de modo mais atrativo, fazendo uso de diversas linguagens, por meio da ludicidade, facilitando a prática docente da geografia, contribuindo assim, para que o estudante seja capaz de pensar a partir de novos paradigmas e como protagonista do espaço social. A proposta parte do entendimento de que o ensino é um processo de construção do conhecimento e o aluno é o sujeito ativo nesse processo. $O$ trabalho discute o lúdico, como elemento fundamental no ensino de geografia, a partir das experiências e vivências no Programa Institucional de Bolsa de Iniciação à Docência (PIBID), no ano de 2018,2019 em uma escola pública da rede municipal de Ensino Fundamental, campo de estágio, no município de Garanhuns, agreste pernambucano. Trata-se de uma pesquisa qualitativa de análise descritiva e interpretativa. A investigação contou com a participação de 01 professora e de 60 estudantes, de faixa etária de 11 anos, componentes de 02 turmas do $6^{\circ}$ ano, na disciplina geografia. Os dados apontam que, por meio do lúdico, foi possível perceber aprendizagens, a partir de uma maior interação entre professora e estudantes nos conteúdos trabalhados nas aulas.

Palavras-chave: Ensino de geografia; Jogos lúdicos; Outras linguagens.

\section{Ludic Learning In Geography: Possibilities And Limits In Children's Learning}

ABSTRACT

The present investigation has as its objective the proposal of a theoretical-practical 
interaction in the sense of transforming the classroom into a more attractive dynamic for making use of a diversity of language and by way of playfulness. This facilitates the teaching practice of geography, in this way contributing to the student's capacity to think, setting out from new paradigms and as a protagonist of the social space. The proposal sets out from the understanding that teaching is a process of the construction of knowledge and the student is the active subject in this process. The work discusses ludic procedures as a fundamental element in the teaching of geography, using experiences and the life of learning gained from the Institutional Program of Scholarships for New Teachers (PIBID) in 2018. The teaching rounds occurred in a public primary school in Garanhuns, a regional municipality in Pernambuco State (Brazil). This qualitative study uses descriptive and interpretative analysis. The investigation involved the participation of a female teacher and 60 students of Geography of 11 years of age, divided into 2 sixth year classes. Data indicate that by way of the ludic dimension it was possible to perceive learning from a greater interaction between teacher and students in the content worked upon in Geography classes.

Key-Words: Teaching geography; Ludic activities; Other languages.

\section{Notas introdutórias}

As transformações culturais, políticas e sociais que a Educação vem passando afetaram o modo de pensar e de agir do homem e a sua formação. Em meio a todas essas mudanças, elas refletem a respeito da produção e da atualização do conhecimento, no que condiz com a história, e que é preciso ressignificar e socializar saberes.

Neste contexto de transformação e reformas na estrutura de ensino, nós, enquanto professores nas escolas, passamos a perceber que a sociedade requer trabalhar com termos não utilizados no cotidiano da sala de aula e com diferentes formas de apropriação de conhecimentos, bem como atribuir processos criativos, por meio de novos métodos de aprendizagem.

A forma de ensino vem se modificando cada vez mais ao longo dos anos, nesse mundo globalizado e cada vez menor. Assim, a escola, com suas formas de trabalhar currículo de forma tradicional, precisa dialogar com outras linguagens, outros métodos no ensinar, no sentido de mediar novas formas de apropriação e de compreensão de conhecimentos, que possibilitam a formação dos sujeitos, numa perspectiva integral, dinâmica e contemporânea no aspecto do ensinar e do aprender.

Diante disso, indagamos: pensar em outras possibilidades e limites do ensinar em um contexto tradicional, voltado para as políticas educacionais estabelecidas, é também compreender de que forma tais mudanças poderão contribuir para um deslocamento das práticas pedagógicas no cotidiano da escola e buscar ali alternativas para as que já foram criadas?

Argumentamos que o processo de ensino e de aprendizagem passou a exigir das práticas pedagógicas, novas linguagens voltadas para o desenvolvimento de competências e habilidades, em uma relação mútua entre educador e educando. 
As escolas, no seu cotidiano, não podem deixar de desenvolver atividades que contemplem estratégias que contribuam, de fato, para as aprendizagens, por meio de outras propostas metodológicas e que possibilitem que o artístico possa ser desenvolvido com probabilidades de se adequarem a uma forma dinâmica e mais lúdica, constituindo-se em saberes da formação.

Essa ideia tem como objetivo propor a interação teoria-prática no sentido de transformar a sala de aula de modo mais atrativo fazendo uso de diversas linguagens, por meio da ludicidade, facilitando a prática docente da geografia e fazendo uso de jogos no processo do ensinar e do aprender.

O despertar para a escolha do tema, para as ideias aqui desenvolvidas e para os argumentos trazidos para o texto se deu a partir de diversos momentos e situações da trajetória acadêmica e profissional dos pesquisadores, a partir das experiências vividas no Programa Institucional de Bolsa de Iniciação à Docência (PIBID), no ano de 2018 e 2019, em que fizemos uso do lúdico tornando-o elemento central para todas as atividades propostas na disciplina de geografia, no $6^{\circ}$ ano do ensino fundamental na escola campo, junto à professora supervisora que nos aproximou de teóricos que têm, como foco de estudo, o jogo e a ludicidade, articulando essas leituras com o interesse pela prática docente.

Os estudos realizados por Lüdke (2012) apontam que a pesquisa, em ensino, desempenha um papel estratégico na melhoria dos cursos de licenciatura, pois tende a valorizar a formação dos professores em suas experiências vividas e ainda, de acordo com a referida autora, " a literatura específica e até a legislação relativa à formação de professores já admitem a importância da pesquisa na preparação e no trabalho do professor". (LÜDKE,2012, p.30).

Essa experiência de vida tem eco no que postula Bondía (2002, p. 26-27): "O saber de experiência se dá na relação entre o conhecimento e a vida humana. De fato, a experiência é uma espécie de mediação entre ambos”. Acrescenta o referido autor que,

[...] No saber experiência não se trata da verdade do que são as coisas, mas do sentido ou do sem-sentido do que nos acontece. E esse saber da experiência tem algumas características essenciais que o opõem, ponto por ponto, ao que entendemos como conhecimento (BONDÍA, 2002, p. 27).

Para Tardiff (2002), o exercício da docência, por meio das experiências vividas, desperta uma grande variedade de interações que, muitas vezes, possibilitam transformações no profissional e na sua prática. Para Pagni e Brocanelli (2015) um dos meios de garantir a integridade da experiência como um organismo vivo é atentarmos no antes e no depois, tendo em vista sua situação como um novo agente e um novo momento de conhecimentos mais extensos do que anteriormente vividos. Descrevem ainda que, a escola funciona como um laboratório e uma instituição privilegiada para que esses valores éticos democráticos e os significados da experiência sejam testados, de modo a permitir, 
aos agentes, uma experiência educativa, como um laboratório que pode unir teoria e prática na liberdade dos alunos.

Assim, a escola é o espaço onde esses estudantes podem ser protagonistas dessa aprendizagem, instigados com motivações práticas e capacidade cognitiva para possibilitar soluções criativas para a sua formação. Dessa forma, serão instigados a levantar hipóteses, comparar, analisar, avaliar e interpretar, e por meio da divisão das tarefas entre os participantes, se estimula a cooperação e, consequentemente, se desenvolve um espírito social, ao contrário do ensino tradicional que valoriza e preza pela obediência.

No entanto, para promover experiência e significados, o professor deve estar consciente de que o estudante não é um receptor, mas um interlocutor atento. Nesse entendimento, trazemos para a discussão, o lúdico como possibilidade e desafio de uma linguagem interativa do ensino de geografia, como uma forma de utilização e de inserção de recursos didáticos mais dinâmicos, criativos e motivadores e, consequentemente, incidindo sobre as formas de aprender e de interagir para dinamizar o cotidiano na sala de aula.

A construção da caminhada metodológica foi se constituindo por meio de laços de confiança no contexto da escola descrita na metodologia.

\section{O lúdico como elemento mobilizador no ensino-aprendizagem da geografia}

A relação do brincar e do aprender, numa ação mútua entre educando e educador, no contexto da sala de aula e expressa na prática docente exige a tarefa de ambos que, para Fortuna (2011), é a chamada de aula lúdica, e se configura como uma prática que privilegia atividades criativas. Ainda de acordo com a autora, $\{\ldots\}$ o nexo brincar, aprender e ensinar se estabelece quando se conciliam os objetivos pedagógicos, as características essenciais da atividade lúdica e os desejos dos alunos. (FORTUNA, 2011, p.81).

Nesse sentido, se faz necessário encontrar o equilíbrio e a seriedade das funções pedagógicas centradas no ensinar conteúdos e no aprender desses estudantes, contribuindo para o desenvolvimento da subjetividade, trazendo outras formas e atitudes em relação ao conhecimento do mundo, do outro e de si mesmo para construção do ser humano autônomo, criativo e com implicações para o sucesso escolar. Essa forma de inovar o ensino, a partir do conhecimento adquirido da turma, envolve a observação das coisas ao seu redor, compreendendo, assim, a relação social perante seus pontos de vista. Para Cavalcanti (2012), "o objetivo maior do ensino, portanto, é a construção do conhecimento mediante o processo de aprendizagem do aluno" (CAVALCANTI, 2012, p.138) e, assim, o espaço da sala de aula se torna o lócus de inserção de saberes, da descoberta, do estímulo da aprendizagem e da construção de conhecimentos.

Nessa perspectiva, os estudos de França (2008) apontam que a prática docente, expressa com ludicidade, à medida que ela se relaciona com ações desejadas, favorece o estabelecimento de vínculos afetivos entre os envolvidos. 
Desse modo, essas ações visam o ensinar e o aprender, sem esquecer do processo educativo. Para Freire (1994), \{...\} O ensino dos conteúdos implica o testemunho do professor. "A boniteza da prática docente se compõe do anseio vivo de competência do docente e dos discentes e de seu sonho ético". (FREIRE,1994, p.37).

A prática docente lúdica, que faz parte da boniteza descrita por Freire (1994), no âmbito escolar, deve estar de mãos dadas com a seriedade e a responsabilidade da prática que o educador realiza, que, para Santos (2011) é de grande relevância, em função de transformar a sala de aula em momentos mais atrativos, com participação construtiva dos alunos, socializando conhecimentos no ambiente que o cerca de forma prazerosa, não linear, e traz novas perspectivas para o ensino de uma forma geral, motivando a aprendizagem. Nesse contexto, Silva e Muniz (2012) descrevem que é preciso desconstruir a figura do aluno como um agente passivo e reprodutor das palavras do professor e compreendê-lo como um sujeito transformador, que busca construir um conhecimento mutável no tempo e no espaço. O professor precisa desafiar o educando, instigando-o à criticidade e a sua atuação na sociedade. Assim, as contribuições dos recursos didáticos e lúdicos permitem uma maior reflexão para o ensino aprendizagem de geografia com o fim de demonstrar como esses elementos são capazes de despertar o interesse dos alunos e de tornar o ensino da disciplina mais lúdico e mais atraente aos olhos dos mesmos.

Entender a educação de maneira mais humana, discutida na pedagogia da autonomia de Freire (1994) significa propor uma aprendizagem no contexto da sala de aula, e, essa depende, na sua grande parte, do professor, na forma como essa aprendizagem é conduzida, vivida com ética, afetividade e alegria. É a relação entre a atividade docente bem sucedida e a esperança do ensinar e do aprender no espaço pedagógico enquanto processo temporal, dinâmico, transformador e libertador e, para isso, necessário se faz o professor utilizar o círculo dialógico com diferentes fontes de informação e de recursos didáticos (aulas práticas, oficinas, utilização de maquetes, fotografias aéreas, imagens de satélites, recursos lúdicos entre outros), estimulando a vontade de aprender dos estudantes e buscando práticas pedagógicas que permitam hibridizar o conhecimento científico e o cotidiano em que vive e, assim, poder dialogar com o espaço da experiência e da vivência. Para Santos (1995), o espaço deve ser considerado como um conjunto indissociável de que participam, de um lado, certo arranjo de objetos geográficos, objetos naturais e objetos sociais, e, de outro, a vida que os preenche, ou seja, a sociedade em movimento e que deve ser trabalhado em sala de aula.

Para Freitas \& Salvi (2007), é brincando e jogando que o educando expressa, assimila e constrói realidades que o cerca, bem como, possibilita a socialização de conhecimentos, proporcionando, assim, a interação e a participação dos alunos. Para Cruz; Fernandes \& Azevedo (2009), a atividade lúdica facilita o aprendizado do educando, pois, muitas vezes, o conteúdo 
trabalhado em sala de aula, de forma puramente verbal e linear, está sujeito a não ser assimilado totalmente pelos alunos. Para Rego (2011), ensinar com jogos estimula o intelecto, além de representar desafios que põe à prova o participante que se arrisca, testa limites e regras, geralmente combinadas com antecipação ao agir diante de obstáculos, estimulando a superação, permitindo uma aprendizagem dinâmica.

Nesse entendimento, Brougére (2011) descreve que o que caracteriza o jogo é menos o que se busca, e uma das características do jogo consiste efetivamente no fato de não dispor de nenhum comportamento específico que permite separar claramente a atividade lúdica de qualquer outro comportamento. Nesse sentido, o jogo oferece uma aprendizagem para a vida, pois se constitui em um espaço de autonomia, liberdade e, ao mesmo tempo, de submissão às regras estabelecidas.

Levando esses conceitos para um aspecto mais geográfico, os Parâmetros Curriculares Nacionais (PCN) do ensino de geografia traz, em seus escritos, que o professor deve criar e planejar situações de aprendizagem nos vários conteúdos propostos. O documento sugere ainda flexibilização no tratamento dos temas e dos conteúdos, com possibilidades de uso de recursos didáticos, com diferentes fontes uma vez que:

qualquer que seja a concepção de aprendizagem e opção de ensino, estas
deverão estar voltadas à formação plena do educando. Portanto, deve-se
ter sempre o cuidado de deixar claro quais são os métodos mais
adequados que garantem atingir esse grande objetivo (BRASIL, 1998,
p.133).

Para Sacramento (2010), o exercício da docência em geografia, é conseguir organizar os saberes geográficos e articulá-los com os saberes pedagógicos em uma relação mútua de saber docente, saber discente e o saber escolar, por meio da promoção de ações diferenciadas de trabalhar a disciplina na sala de aula, buscando uma melhor reflexão dos conteúdos e dos conceitos escolhidos, fazendo com que o estudante compreenda os fenômenos geográficos presentes em seu cotidiano de diversas formas, permitindo-lhe localizar-se e perceber tais transformações e, assim, atingir o objetivo que é a aprendizagem do aluno. Coltrinari (2004) destaca que é preciso ensinar a pensar interdisciplinarmente, a descrever adequadamente, pois as experiências concretas dos alunos devem ter interligação e coerência sobre o que é ensinado, pois o vivido pelo aluno é expresso no espaço cotidiano fundamental para a aprendizagem.

De acordo com Castrogiovanni e Callai (2007), o ato de ensinar, como fenômeno social, exige não apenas o conteúdo específico do livro didático, mas coragem de ousar no ato do ensino, acreditando que a educação tem finalidades além da sala de aula. O professor deve ter a capacidade criativa, coerente com a prática, na busca de novas metodologias, fazendo uso de outras linguagens no sentido de despertar no estudante um olhar inquieto sobre textos e contextos ensinados e experenciados, e sobre a vida, incitando curiosidades sobre o mundo 
em que vive considerando o contexto individual e coletivo pautado no ensino, pesquisa e extensão.

Dessa forma, o docente precisa articular os saberes geográficos com o cotidiano do estudante. Para tal fato ocorrer, o mesmo pode construir outras linguagens para a realização de aulas diferenciadas e mais dinâmicas. Nessa perspectiva, o educador, ao utilizar o lúdico como elemento facilitador construtivista do ensino-aprendizagem, traz, para o dia a dia da sala de aula e dos estudantes, formas diferentes de ensino, não lineares, que geram maior interesse e participação dos mesmos. Assim, trabalhar o lúdico por meio de jogos no $6^{\circ}$ ano do ensino fundamental aborda mecanismos de aprendizagens facilitadoras, com metodologias inovadoras de conhecimentos, de forma divertida e cooperativa, principalmente, como instrumento de percepção do espaço geográfico.

Dito isso, concordamos com Santaella (2012), quando aponta que o ato de jogar encontra um alto nível de motivação intrínseca e recompensa de novas aprendizagens cognitivas dentro de um contexto, e o lúdico é o elemento que lhe fornece potência, no qual cada jogador se sente protagonista do seu espaço.

Ressaltamos que o jogo oportuniza, ao estudante, a assimilação de conceitos geográficos, muitas vezes não assimiláveis no contexto da sala de aula, além de permitir a vivência de situações de controle e regras, ensinando conceitos de moral e de ética, em um intercâmbio com o outro. Para Macedo (2005), ao jogar, o estudante é levado a exercitar suas habilidades mentais e a buscar melhores resultados para vencer, mobilizando todo o ser do jogador e o desafiando para a construção do conhecimento. Muitos jogam não para aprender, apesar de que o façam, mas para sentir a emoção e a sensação de estar no grupo. Além disso, há aqueles que se motivam nessa prática para arriscar, e sentir as expectativas de alcançar o inesperado. Assim, para o educador, trabalhar na perspectiva lúdica significa ser possível ressignificar a prática docente de geografia.

\section{Metodologia}

\section{Configuração da Pesquisa}

A pesquisa se pautou numa abordagem qualitativa no entendimento de que a mesma se fundamenta na relação direta do sujeito objeto, ancorada numa concepção epistemológica de autores que nortearam a construção do conhecimento. Assim, no sentido de verificar a adequação dos objetivos pretendidos, utilizamos, como ponto de partida, conhecer o ambiente da pesquisa, a partir de uma visita, previamente, programada com a direção. No período de 02 dias, fizemos observações, acerca da estrutura física da escola, realidade dos estudantes e realidade da professora e da comunidade escolar. Também foi objeto de nossa observação, o entrosamento com os discentes na hora do intervalo e algumas intervenções no espaço da sala de aula das 02 turmas do $6^{a}$ ano. Tais observações, com respeito, empatia e descrição no diário de bordo permitiram um contato direto e uma familiarização entre pesquisadores e os participantes, que, 
para Minayo (2004), na pesquisa qualitativa, o conjunto de unidades interpretativas dos fenômenos e atribuição dos significados se encontra em destaque no olhar do pesquisador em relação aos pesquisados, em uma retroalimentação e ajustes ao longo da sua execução, capazes de gerar mais resultados e pesquisas.

O campo de pesquisa, foi uma escola pública do município de Garanhuns agreste pernambucano. O recorte temporal teve o período de agosto de 2018 a dezembro de 2019, cuja pesquisa contou com 02 estudantes e 01 professora pesquisadora do curso de licenciatura em geografia e 01 professora orientadora líder do Grupo. Trata-se do Grupo de Pesquisa A Cultura da Infância nas Políticas Pedagógicas da Educação Infantil (GUPEI) da Universidade de PernambucoUPE/Campus Garanhuns, agreste pernambucano, Nordeste do Brasil.

Optamos pela realização da pesquisa no ambiente escolar, por entendermos que a escola, historicamente, representa o espaço de socialização de conhecimentos e convivências, cujo lócus foi a sala de aula por esta se constituir como um espaço de múltiplas relações, determinações e interações, que, em nosso caso, envolveu duas turmas do $6^{\circ}$ ano do ensino fundamental, com 30 estudantes, juntas perfazendo um total de 60 alunos de ambos os sexos com média de idade de 11 anos. É importante esclarecer que todos os jogos trabalhados nessa pesquisa foram discutidos e analisados à luz do conteúdo da disciplina geografia, pela equipe gestora e professora da escola

No tocante às falas e aos depoimentos dos estudantes, esse momento ocorreu em um clima de total confiança, estabelecido desde os primeiros momentos da observação no ambiente da escola e foram motivadores para as considerações finais, e analisados na perspectiva descritiva, que, para Gil (2008), esse tipo de pesquisa, pela sua intensidade de atuação, não se encerra somente com um relatório descritivo e analítico, podendo gerar outros planos de ação, o que permite a identificar como uma pesquisa qualitativa.

O instrumento construído para interagir com a professora da escola e, compreender sua opinião, concepções, expectativas, percepções sobre a experiência na pesquisa, foi a entrevista semiestruturada. Por meio desta, buscamos estabelecer um diálogo intencional, previamente estruturado, embora flexível, registrado por meio da gravação, no sentido de não perder detalhes da entrevista.

No processo de análise, nos apoiamos na técnica de análise de conteúdo de Bardin (1997). Primeiramente, foi feita uma pré-análise da entrevista e a transcrição dos dados anotados, privilegiando as categorias mais abordadas. Após esse momento, fizemos a escuta panorâmica das falas gravadas para subsidiar o contexto e tratamento da entrevista e da interpretação dos dados.

As leituras que serviram de referências para o construto da investigação, possibilitaram desmistificar os desafios do tema da pesquisa em uma proposta de trabalho complementar ao da escola, que vai possibilitar caminhos e reflexões para outras práticas do ensinar e do aprender geografia. 
Os estudantes foram divididos em grupos de 05 participantes, livremente escolhidos pelos pares. Assim, desenvolvemos, com os mesmos, 05 aulas/oficinas com duração total de 10 horas, no período da tarde, entre os meses de outubro e novembro de 2018. É importante destacar que essa organização foi definida nas quartas-feiras, em função do horário da escola e da disciplina geografia.

\section{Etapas da pesquisa}

Estas ocorreram em quatro etapas. A primeira se referiu à observação do espaço da escola, contatos com o corpo administrativo e encontros com a professora nos momentos de intervalo para seleção dos conteúdos de geografia, trabalhados no $6^{\circ}$ ano do ensino fundamental, cujo critério foi estabelecido a partir dos que apresentavam, por parte dos estudantes, difícil compreensão, tendo em vista a polissemia de conceitos que os envolve, tais como: região; regionalização; domínios morfoclimáticos do país; estados e capitais brasileiras. Após essa etapa, chegamos ao acordo sobre as atividades e os jogos que poderiam ser desenvolvidos com os mesmos.

A segunda se referiu à delimitação da proposta da pesquisa, junto ao corpo da escola com a presença da direção e da professora. Assim, foram definidos os temas e a seleção de jogos, de acordo com o conteúdo trabalhado previamente pela professora e o interesse dos estudantes. Necessário se faz descrever que o suporte do material didático para a construção dos jogos, tal como cartolina, cola, tesouras, barbantes, canetas hidrocor, entre outros, foi subsidiado pela escola e, construído pela equipe de pesquisadores, professora e estudantes.

A terceira etapa diz respeito à construção de alguns jogos, pela equipe da pesquisa, juntamente com os estudantes do $6^{\circ}$ ano, que envolveu pesquisa no livro didático, de acordo com o conteúdo trabalhado pela professora e seleção de revistas para a identificação e recorte das paisagens utilizadas no jogo.

A quarta etapa se referiu à aplicação dos jogos como atividade didática, assim descritos: Jogo das três pistas: domínios naturais do Brasil; Jogo de Quebra-cabeça: regiões do Brasil; Jogo de Dominó: conceitos geográficos; e Jogo da memória: estados e capitais do Brasil. Detalhados a seguir.

\section{Análise dos resultados}

O jogo representa um material lúdico, que desperta a atenção em várias faixas etárias, mas, quando aliados ao processo de ensino e de aprendizagem, seu potencial ressignifica o contexto da sala de aula, aumenta a motivação dos estudantes para enfrentar situações de erros e acertos, contribui significativamente para o desenvolvimento cognitivo e percepção, bem como coopera no controle de emoções, desenvolvimento do respeito e interação com a equipe participante. Por meio dos jogos, foi possível perceber muitas situações de novas aprendizagens, entre os estudantes, diante dos conteúdos trabalhados em sala de aula. Assim, o grupo de pesquisa, junto com a professora da classe, pôde perceber mecanismos e situações espontâneas dos estudantes, tais como, brincadeira, descoberta de 
regras, autoestima e cooperação mútua, desencadeando experiências com jogos. Alguns, já vivenciados em outras situações por eles relatadas.

Do conjunto da descrição dos relatos das falas dos participantes, realizamos inferências sobre as mesmas, além da interpretação e descrição, dos dados( MINAYO,2004;BARDI,1997;GIL,2008).Assim, foi possível perceber o interesse de participar dos vários jogos apresentados, bem como a similaridade entre os depoimentos da professora e dos estudantes, que serviram de subsídios para a construção da pesquisa.

A análise dos dados foi organizada em quatro momentos, cuja intenção foi descrever a importância da prática docente expressa com ludicidade, que contemplasse conteúdos da disciplina geografia do $6^{\circ}$ ano, buscando situações didáticas, em cada jogo, expressas nas falas da professora e dos estudantes, as quais daremos destaque ao final da apresentação e do procedimento de cada jogo.

\section{Jogo das 3 pistas: domínios naturais do Brasil}

Essa atividade lúdica despertou para o entendimento de diferentes áreas de conhecimento, no contexto da geografia física e humana em um imbricamento constante, cujo entendimento exige pensar, refletir e contextualizar categorias da ciência geográfica, contribuindo também para a compreensão do espaço geográfico, onde a escola se localiza e para o cotidiano dos estudantes. Esse jogo, teve como objetivo trabalhar o conteúdo dos domínios naturais do Brasil, em suas diferentes regiões, e foram discutidos os conhecimentos de clima, relevo e vegetação.

O jogo consiste em cartas que contêm três (03) pistas referentes ao tema, Domínios da Natureza, no qual o estudante precisa desvendar o conteúdo da pista dada e para qual região se insere esta pista por meio de estímulos.

Nessa proposta de jogo, a turma foi dividida em dois grupos, e cada grupo escolheu cinco participantes. Foram elaboradas sete cartas, contendo cada uma três pistas sobre o assunto, conforme quadro 1 que apresentamos mais à frente. Diante das cartas (enumeradas de 1 a 7 ), a professora, como mediadora, fez o par ou ímpar entre os dois grupos, elegendo o número par ou ímpar como ganhador. Em seguida, inicia o jogo, solicitando que o grupo ganhador escolhesse uma carta.

$\mathrm{Na}$ sequência, a professora fez a leitura da primeira pista (valendo 15 pontos). Se o grupo não soubesse responder, a mesma pergunta iria para o próximo grupo, acrescentada da segunda pista (valendo 10 pontos). Caso este não soubesse, a carta iria novamente para o grupo iniciante, que teria acesso à terceira pista (valendo 5 pontos). Se, nenhum dos grupos acertasse, a pista seguiria para o restante da turma que, enfileirados, passariam a responder. Nesse caso, a pontuação de 5 pontos seria do grupo que aquele estudante respondeu. Ao final foram contabilizados os pontos e ganhou o jogo o grupo que contabilizou maior número de pontos. Por fim, a equipe vencedora fez a leitura do quadro concluído para todos os participantes, contextualizando as respostas com os conteúdos 
trabalhados.

Quadro 1 Jogo das 3 pistas: domínios naturais do Brasil
1)Apresenta matas fechadas e densas;
1)Ocorre no oeste do Nordeste e norte de Minas Gerais;
2) Vegetação diversa;
2) Clima semiárido;
3) Elevado índice pluviométrico.
3) Longa estiagem e chuvas irregulares
R: Domínio Amazônico
R: Domínio da Caatinga
1) Centro-oeste do Brasil;
1) A paisagem é formada por relevo acidentado;
2) O clima é o tropical subsumido;
3) $O$ relevo por planaltos e chapadas.
2) Clima é o tropical úmido;
3) Chuvas são regulares e bem distribuídas
R:Domínio do Cerrado
R: Domínio dos Mares e Morros
1) Região Sul do Brasil;
2)Encontrada principalmente em planaltos mais elevados;
3) Verões quentes e invernos rigorosos.
R: Domínio das Araucárias
1) Vegetações rasteiras e gramíneas;
2) Relevo relativamente plano, suavemente ondulado;
3) Clima subtropical.
1) Apresenta características variadas;
2) O relevo que predomina são as planícies;
3) Alagam nos períodos chuvosos.
R: Faixa de transição (pantanal)

\section{Jogo de Quebra-cabeça: regiões do Brasil}

Nesse jogo, trabalhamos o mapa do Brasil dividido em suas 5 regiões. Este, consistiu em organizar peças, em papel cartolina, das regiões brasileiras disponíveis e embaralhadas de maneira que se chegasse a formar uma figura completa do mapa do Brasil. Esse jogo, envolve conceitos de região, trazendo para a discussão o conhecimento das regiões do Brasil, suas características físicas espaciais e a localização, envolve conhecimentos da Rosa dos Ventos que é um instrumento antigo utilizado para auxiliar na localização geográfica em mapas e cartas composta pelos pontos cardeais,(norte, sul, leste, oeste); colaterais (nordeste, sudeste, sudoeste e noroeste) e, subcolaterais. Segundo a professora "trabalhar a rosa dos ventos é muito polêmico para se contextualizar na sala de aula".

Daí os estudantes procuravam encaixar as peças do quebra cabeça para formar o mapa do Brasil tendo como estímulo uma característica da região. À proporção que iam encaixando o quebra cabeça, os estudantes iam escrevendo o nome da região encaixada, corretamente com as características físicas, humanas e territoriais. O objetivo desse jogo foi trazer para a discussão o entendimento sobre região e regionalização, bem como as características físicas, humanas de cada uma delas. Nessa atividade, houve a intervenção da professora que pôde discutir a regionalização do Brasil e destacar conhecimentos importantes para a construção da disciplina.

Assim, por meio desse jogo, foi possível perceber como os estudantes se empoderam, discutem e questionam os contrastes regionais do Brasil, bem como percebem as potencialidades de cada região, construídas a partir do processo de entendimento coletivo. 


\section{Jogo Dominó: Conceitos Geográficos através do lúdico}

O jogo de dominó é composto por peças retangulares divididas em duas partes ou faces (como são chamadas no dominó original). Nesse jogo, foi trabalhado conteúdos de domínio morfoclimático, assim descrito: em uma face, encontram-se paisagens, e na outra face, um texto. Cada paisagem se encaixa com um texto específico de suas características

Esse jogo busca despertar no estudante a interpretação de paisagens e relacioná-las ao domínio morfoclimático, bem como trabalha com dois tipos de leitura: a leitura textual e a leitura da percepção de paisagem. É importante destacar que esse jogo foi confeccionado pelos estudantes, com o objetivo de que estes correlacionassem, previamente, a paisagem com a descrição geográfica da mesma. Nessa atividade, foi possível perceber a interação entre os estudantes, permitindo perceber o espaço geográfico a partir do local até o global, na construção do conhecimento. Esse momento também estimulou o aprendizado dos conceitos de paisagem natural e facilitou a percepção das transformações que nelas ocorreram, incluindo questões ambientais que são discutidas em geografia, como temas transversais.

Esse tipo de atividade trouxe a interação da teoria com a prática e o protagonismo dos estudantes no processo ensino-aprendizagem, contextualizando os conteúdos discutidos na sala de aula, na proposta do lúdico.

\section{Jogo da memória: Estados e Capitais do Brasil}

Para a realização desse jogo, a equipe de pesquisadores, junto com a professora, fez uso de cartões retangulares de papel cartolina em que foram colocados os nomes dos estados e das capitais do Brasil. Os cartões foram embaralhados e virados de cabeça para baixo e colocados sobre a mesa. Daí cada participante, por sua vez, deveria virar duas cartas correlacionando o estado e a sua respectiva capital. Caso não correspondesse, as cartas voltariam para o mesmo local. Ganhava o jogo o participante que tivesse mais pares de cartas que constassem o estado e a sua referida capital.

Nesse jogo, foram trazidos contextos em cada momento da virada das cartas em que cada estudante teria que narrar, para os demais participantes, seu entendimento sobre aquele estado e a referida capital. Para a surpresa da equipe e da professora os estudantes, trouxeram para discussão, assuntos relacionados as desigualdades regionais de cada estado, bem como características culturais das capitais, e aspectos populacionais e econômicos segundo o entendimento deles, e, com o olhar atento da professora que questionou várias proposições, o que caracterizou a atividade mais divertida.

Assim, as atividades lúdicas trabalhadas no ambiente da sala de aula, possibilitaram perceber que tais atividades não constituem uma brincadeira ou o que dela resulta. Isso significou refletir sobre os conteúdos da disciplina geografia e que os mesmos podem ser trabalhados com outras metodologias no contexto da 
sala de aula. Na fala da professora, foi possível constatar essa transformação de ensinar e de aprender dos estudantes, quando a mesma argumenta que:

\begin{abstract}
Através dessa proposta didática foi possível compreender a geografia tradicional colocada nos livros didáticos, com relação ao estudo de estados e capitais do Brasil, que não traz relação nas diferenciações que muitas vezes foram vividas pelos alunos.
\end{abstract}

Cabe inferir que a relevância do lúdico como recurso didático, no ensino de geografia do $6^{\circ}$ ano, possibilitou a interação teoria e prática. Destacamos ainda que as atividades de aprender por meio de jogos, possibilitam momentos de integração dos envolvidos por inteiro, estando flexíveis à aprendizagem. Nesses jogos, os participantes foram parceiros na construção do conhecimento, elaborados criativamente, advindo da sala de aula e fora dela, em uma aprendizagem voltada para o aprender brincando. Cabe destacar que a participação em equipe foi primordial para o desenvolvimento pessoal e coletivo dos estudantes e da pesquisa.

Assim, a partir dos depoimentos e da análise da entrevista da professora, com relação à prática pedagógica com o lúdico, foi possível perceber a importância de se trabalhar com jogos no ensinar e aprender geografia conforme descrito abaixo:

1:trabalhar com jogos na perspectiva de vivenciar um ambiente de aprendizagem lúdico no ensino de geografia, principalmente no entendimento das regiões do Brasil, foi significativo, tendo em vista que esse conceito é polissêmico e traz, em seu discurso, elementos naturais e sociais, que se configuram como um dos maiores desafios para ser trabalhado no contexto da sala de aula, levando o estudante para a decoreba (depoimento da professora);

20 lúdico, como recurso didático, é uma boa experiência enquanto prática pedagógica e integração da turma ao despertar aprendizagens. Atinge a proposta do conteúdo trabalhado e os alunos se divertem. Quero trazer alegria para esses alunos (depoimento da professora);

3 As dificuldades inerentes à prática e à interação com a turma, torna-se bem menor quando utilizamos o lúdico como meio de entendimento e um despertar para as aprendizagens (depoimento da professora).

As narrativas da professora revelam que trabalhar com o lúdico no ensino de geografia representa uma prática prazerosa de ensinar e de aprender, bem como o olhar geográfico desperta no estudante, enxergar o que não vê. E, que trazer para o ambiente da escola outras linguagens e, respectivamente, novas metodologias, ressignifica o ensino, a partir do chão da escola e que, o lúdico, utilizado pelo professor em sala de aula, torna-se um meio para a realização dos objetivos educacionais. Assim, o aluno, ao praticá-lo, não se limita ao prazer de jogar, mas participa ativamente do processo de construção do conhecimento, expressa emoções, entusiasmo e desafios que são importantes para o aprendizado.

Diante do exposto, foi visível perceber, nas falas dos estudantes, que, 
aprender com o lúdico proporciona no contexto da sala de aula, a importância de querer fazer, querer participar e querer ganhar. A seguir, destacamos algumas falas de estudantes no que se refere às vivências e experiências nas aulas de geografia com atividades lúdicas.

\begin{abstract}
Eu não sabia que geografia era tão fácil (Estudante do $6^{\mathrm{a}}$ ano A, 2018).
Bastou algumas dicas para que eu buscasse alternativas e resolvesse essa questão (Estudante do $6^{\mathrm{a}}$ ano B, 2018).

A princípio, tive certa dificuldade no jogo das três pistas devido à falta de prática, mas com o passar das dicas ganhei fácil Estudante do $6^{\circ}$ ano $\mathrm{A}$, 2018).

A princípio, tive certa dificuldade em participar devido à falta de prática, de não saber jogar e de interagir com a turma. Depois, a ajuda da professora, me fez atentar para participar e ganhar. (Estudante do $6^{\circ}$ ano B, 2018).
\end{abstract}

Os resultados mostraram que a utilização de jogos no ensino de geografia no $6^{\circ}$ ano do ensino fundamental, na relação teoria-prática, transforma a sala de aula, como elemento facilitador à prática docente, fazendo uso de diversas linguagens, ou seja, permite trazer para o contexto os conhecimentos prévios dos estudantes, e, mais que isso, proporcionou um contexto facilitador para a expressão de emoções positivas, como motivação, entusiasmo e desafios, que são importantes para o aprendizado.

\title{
Considerações finais
}

A pesquisa teve como ponto de partida propor a interação teoria-prática, no sentido de transformar a sala de aula mais atrativa, fazendo uso de diversas linguagens, por meio da ludicidade e facilitando a prática docente da geografia, do $6^{\circ}$ ano, contribuindo, assim, para que o estudante seja capaz de pensar, a partir de novos paradigmas e como protagonista do espaço social. Além disso, a investigação permitiu refletir sobre a importância de se trabalhar com outras metodologias e de se deslocar as ideias nos espaços tradicionais das escolas, consideradas pelos professores, em seus discursos, como espaços recorrentes e comuns.

Essa reflexão também representou tarefa difícil de fazer, diante do cotidiano da escola, engessado pelo sistema de ensino tradicional, bem como a formação continuada dos professores que, na maioria das vezes, não trazem para seu contexto a diversidade de conhecimentos teórico metodológicos a serem elaborados e recriados para se transformarem em saberes escolares.

Considerando a importância que a atividade lúdica tem na formação dos estudantes, na escola básica, a pesquisa envolveu a usualidade de jogos e brincadeiras, na proposta de facilitar a compreensão referente ao conteúdo da disciplina geografia, abordado em sala de aula do $6^{\circ}$ ano. Essa intervenção foi bastante significativa, considerando que, no exercício dessa prática, foi se 
contextualizando não só os conteúdos da disciplina geografia, mas também o desenvolvimento do estudante, o qual é um ser capaz de pensar a partir de novos paradigmas, e como protagonista do espaço social. Isso permitiu habilidades favoráveis à aprendizagem dos conteúdos vividos e aprendidos e a socialização da professora e dos estudantes, no trabalho em grupo.

Assim, houve o incentivo à realização das atividades que envolvessem a socialização e o trabalho em grupo, saindo do tradicional quadro branco na sala de aula e trazendo a ludicidade como elemento da profissionalidade docente na geografia. Cabe ainda lembrar que, as atividades lúdicas na sala de aula não são simplesmente uma brincadeira, mas são momentos de socialização e de aprendizado, que requerem planejamento por parte do(a) professor(a) para contextualizar o conteúdo a ser trabalhado da disciplina e atingir os objetivos propostos. Percebemos também, dessa forma, que a sala de aula é um laboratório de pesquisa, intervenção, e de campo de conhecimentos, na relação teoria-práticaação, mas é preciso estabelecer diálogos de aproximações no planejamento das aulas.

Os dados sinalizam a efetivação dos objetivos propostos e indicaram que as aulas ficaram mais atrativas durante as dinâmicas das atividades lúdicas, favorecendo o maior aproveitamento e compreensão dos conteúdos das aulas de geografia. A partir do que foi proposto, percebemos a inserção e a participação dos estudantes nas atividades com bastante adesão a cada uma delas, o que revela a necessidade de transformar o ensino no contexto da sala de aula, por meio de outras linguagens e metodologias.

Assim, consideramos que o lúdico se constitui como uma linguagem interativa que, utilizada no ensino de geografia, produziu resultados, que foram refletidos na melhoria do aproveitamento e nas avaliações do conteúdo, bem como a disposição da turma que agora é $7^{\circ}$ ano.

Temos assim, desafios para enfrentar, pois a pesquisa aponta para a existência de uma lacuna no que diz respeito ao estudo e à inserção do lúdico no contexto da academia durante a formação do educador, face às pressões ideológicas que o currículo sofre, na perspectiva do conteudismo, tanto no âmbito da formação inicial de professores quanto das Secretarias de Educação, pois não podemos ignorar a função política da educação, que tem sido mais voltada à adequação do que à transformação social.

Por último, cumpre observar um ponto que naturalmente decorre do que acabamos de considerar fundamental para a proposta da pesquisa, que é a necessidade de socializar discussões e inquietações, no tocante à práxis desse tema no universo da educação básica e acreditamos que nossas reflexões somarão às outras pesquisas nessa área de estudo que, embora se debrucem sobre outras temáticas, têm as mesmas preocupações potencialmente relevantes na relação teoria e prática na escola básica.

Diante do exposto, para garantir a permanência da proposta da pesquisa, a 
equipe decidiu deixar uma cópia da metodologia do trabalho para a professora e a direção da escola no entendimento de que haverá continuação.

\section{Referências}

BARDIN, Laurence. Análise de conteúdos. Lisboa: Edições 70, 1977.

BONDÍA. Jorge Larrosa. Notas sobre a experiência e o saber de experiência. Revista Brasileira de Educação. №19. Jan/Fev/Mar/Abr, 2002. Disponível em: $<$ http://www.scielo.br/pdf/rbedu/n19/n19a02.pdf>. Acesso em: 05 ago. 2016.

BRASIL, Secretaria de Educação Fundamental. Parâmetros curriculares nacionais: Geografia. Brasília: MEC/ SEF, 1998.

BROUGÉRE, Gilles. A criança e a cultura lúdica.In:KISHIMOTO,Tizuko Morchida (Orgs) et.al. O brincar e aprender teorias. São Paulo: CENGAGE Learnig,2011, P. 19-32.

CASTROGIOVANNI, Antônio Carlos;CALLAI, Helena Copetti. Ensino de Geografia: Práticas e textualizações no cotidiano. 7. Ed. Porto Alegre: Mediação. 2007. p. 11-119.

CAVALCANTI, Lana de Souza. 0 ensino de geografia na escola. Campinas,SP: Papirus, 2012.(Coleção Magistério: Formação e Trabalho Pedagógico).

COLTRINARI, Lylian Zulma Doris, A pesquisa acadêmica, a pesquisa didática e a formação do professor de geografia. In: PONTUSCHKA, Nídia Nacib; OLIVEIRA, Ariovaldo Umbelino. (Orgs) Geografia em perspectiva: ensino e pesquisa.2 ${ }^{a}$ Ed.São Paulo: Cortex,2004,p.115-118.

CRUZ, Gabriel Souza.; FERNANDES, Isabela Duarte; AZEVEDO Júnior Roberto, Sete. Construção de materiais didáticos para o ensino de geografia: $O$ jogo da memória e dos domínios morfoclimáticos. Revista Tamoios, Rio de Janeiro, ano V, n.1, p. 77-82.2009.

FORTUNA, Tânia Ramos. A formação lúdica docente e a universidade: contribuições da ludicidade e da hermenêutica filosófica. 2011. Tese (Doutorado em Educação) -Faculdade de Educação- Universidade Federal do Rio Grande do Sul, Porto Alegre,2011.

FRANÇA, Daise Lima. de Andrade. A prática docente expressa com ludicidade: um repensar sobre as regras do jogo educativo na escola pública. 2008.147f. Dissertação (Mestrado em Educação) - Universidade Federal de Pernambuco, Recife, 2008.

FREIRE, Paulo. Pedagogia da Autonomia: saberes necessários à prática educativa. São Paulo: Paz e Terra, 1994.

FREITAS, Eliana Sermidi; SALVI, Rosana Figueiredo. A ludicidade e a aprendizagem significativa voltada para o ensino de geografia. Portal Educacional do Estado do Paraná. 2007.

GIL, Antonio Carlos. Métodos e Técnicas de Pesquisa Social. $6^{a}$ ed. São Paulo: Atlas, 2008. 
LÜDCKE, Menga. A complexa relação entre o professor e a pesquisa. In: ANDRĖ, Marli (Org) $O$ papel da pesquisa na formação e na prática dos professores. $12^{\mathrm{a}}$ ed. Campinas SP: Papirus,2012.

MACEDO, Lino de: PETTY, Ana Lúcia Sicoli;PASSOS, Norimar Chiste. Os Jogos e o lúdico na aprendizagem escolar. Porto Alegre: Artimed,2005.

MINAYO, Maria Cecília. $O$ desafio do conhecimento em saúde: pesquisa qualitativa em saúde. São Paulo: HUCITEC, 2004.

PAGNI, Pedro Angelo; BROCANELLI Claudio Roberto. Filosofia da educação e educação filosófica, segundo John Dewey. In: PAGNI, Pedro Angelo; SILVA, Divino José da Silva (Orgs) et al.In. Introdução à filosofia da educação: temas contemporâneos e história. São Paulo: Avercamp,2015, p. 216-242.

REGO, Teresa Cristina. Vygotsky: uma perspectiva histórico-cultural da educação. $25^{\mathrm{a}}$ ed. Petrópolis: Vozes, 2011.

SACRAMENTO, Ana. Claudia. Ramos. Didática e educação geográfica: algumas notas. UNI Pluri/Versidad, vol.10, n.3,2010.

SANTAELLA, Lúcia. O papel do lúdico na aprendizagem Revista Teias, Rio de Janeiro, $n^{\circ}$ 30. v. 13, p. 185-193, set./dez. 2012.

SANTOS, Milton. Território, globalização e fragmentação. São Paulo: Hucitec/ANPUR,1995.

SANTOS, Santa Marli Pires dos (Org.) Brinquedoteca: o lúdico em diferentes contextos, $15^{\mathrm{a}}$ ed. Petrópolis: Vozes, 2011.

SILVA, Vládia da; MUNIZ, Alexsandra Maria Vieira. A Geografia escolar e os recursos didáticos: o uso das maquetes no ensino aprendizagem da geografia.

GEOSABERES, Fortaleza, v. 3, p. 62-68, 2012. Disponível em:

<https://www.redalyc.org/pdf/5528/552856435008.pdf>. Acesso em: 10 out. 2018.

TARDIF, Maurice. Saberes docentes e formação profissional. Petropolis, RJ: Vozes, 2002. 


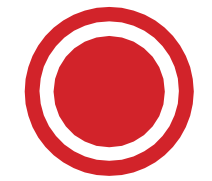

